\title{
First Degree Relative
}

National Human Genome Research Institute (NHGRI)

\section{Source}

National Human Genome Research Institute (NHGRI). First Degree Relative.

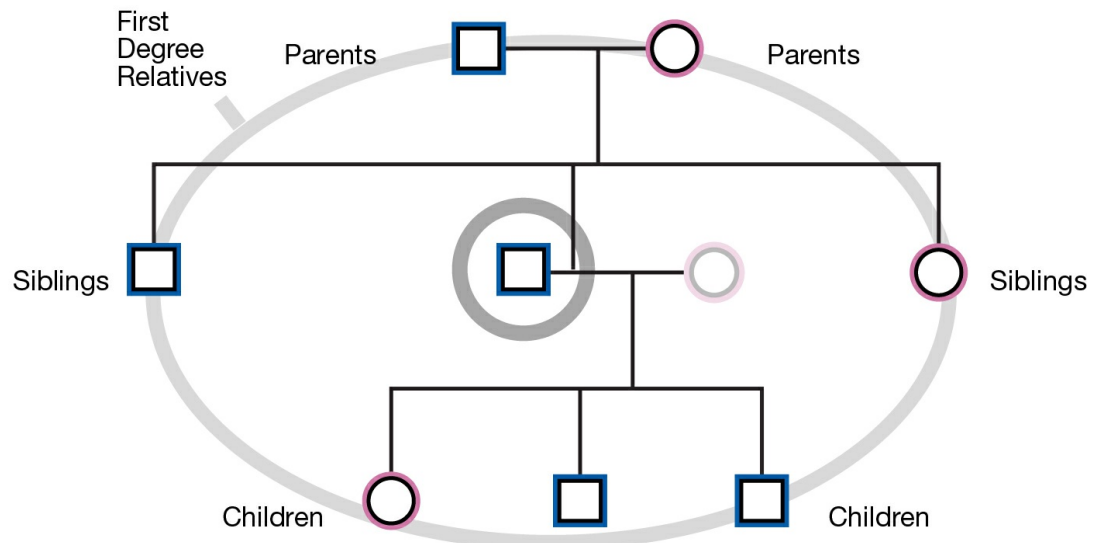

A first degree relative is a family member who shares about 50 percent of their genes with a particular individual in a family. First degree relatives include parents, offspring, and siblings. 